\title{
Modernidade e pós-modernidade: promessas, dilemas e desafios à condição humana
}

\section{Modernity and post-modernity: promisses, dilemas and challeng to human condition}

\author{
Karin Alves do Amaral Escobar
}

Artigo

Original

Original

Paper

Palavras-chave:
Modernidade
Pós-modernidade
Consequências
humanas

Resumo

Pretende-se, no presente trabalho, abordar as características da Modernidade e da Pós-modernidade, realizando-se uma reflexão acerca das consequências da modernidade à existência do homem e problematizando a discussão de como as promessas da modernidade e o processo de globalização têm interferido no posicionamento do homem no contexto da sociedade pósmoderna. Para esse propósito, parte-se da discussão do que veio a se constituir o período denominado modernidade, que tem como marco inicial o advento da revolução francesa (séc. XVIII). Os avanços tecnológicos do século XVIII fizeram surgir um novo mito, a ideia de progresso a partir do pensamento iluminista. Em meados do século XVIII, o capitalismo foi se consolidando em diversos países, esse processo de transformação, do qual está vinculado a Revolução industrial, atinge amplos setores da economia. Paralelamente, a expansão e a consolidação do capitalismo trouxeram, também, novas formas de exploração do trabalho humano, gerando conflitos entre a burguesia e os trabalhadores. Os complexos caminhos da sociedade contemporânea nos colocaram diante de questões como as desigualdades sociais, entendendo que a pós-modernidade deve ser a insistência num questionamento crítico da sociedade moderna, das suas desigualdades sociais e das formas de participação no debate político.

\begin{abstract}
It is intended in the present work to approach the characteristics of Modernity and post-modernity carrying through a reflection concerning the consequences of modernity to the existence of the man. Questioning the quarrel of as the promises of modernity and the process of globalization it has intervened with the positioning of the man in the context of the aftermodern society. Part of the discussion about the constitution of the period known as Modernity, which starts with French revolution (18th century). The technological advances of 18 th century have created a new myth, progress from the Enlightenment ideas. From middle 18th century, capitalism was consolidated in many countries. This process of transformation, which is linked to the Industrial Revolution, affects many sectors of the economy. At the same time, capitalism's expansion and consolidation brought new ways of human labor's exploitation, creating conflicts between bourgeoisie and workers. The complex paths of contemporary society put us in front of questions like social differences, understanding that Post-Modernity must be insistent on a critical questioning of modern society, of its social differences and ways of participating on political debate.
\end{abstract}

Key words:

Modernity

Post-modernity

Consequences

human beings 


\section{Revolução Francesa e Iluminismo: marcos da era moderna}

A modernidade tem início com o advento da revolução francesa (séc. XVIII) que vem marcar mudanças de ordem política econômica, social e cultural, pondo fim ao Antigo Regime ${ }^{1}$.

A Revolução Francesa pode ser caracterizada como a tomada do poder pela burguesia, classe social emergente que fornecia os recursos humanos e financeiros para a sustentação dos Estados, mas, contudo, não haviam ainda conquistado poder político e igualdade jurídica. Os Estados europeus ocidentais sobreviviam graças às atividades realizadas pelos burgueses e trabalhadores, mas, por outro lado, os maiores benefícios políticos, econômicos e jurídicos estavam nas mãos da nobreza e do clero.

Foi nesse contexto que alguns pensadores formularam um conjunto de teorias políticas como iluminismo. Esses pensadores, na grande maioria, eram de origem burguesa e defendiam a crença na razão como promotora de progresso e da felicidade, a rejeição ao governo absolutista e aos privilégios da nobreza e do clero, e também a crítica à interferência da igreja nas questões de Estado.

Os iluministas eram favoráveis ao governo constitucional (regido por leis), o qual protegeria os cidadãos contra os abusos do poder, independentemente da forma de governo, monárquico ou república. Embora se preocupassem com a questão da liberdade, a maior parte deles não defendia uma ampliação de participação popular no poder, por dúvida da capacidade de administração política das pessoas mais pobres.

Baseado nessas ideias traduzidas na Revolução Francesa com o seu lema "Liberdade", igualdade e "fraternidade" a burguesia chega ao poder. A ascensão social da burguesia e sua tomada de consciência como classe social foi acompanhada pela expansão capitalista do século XVII e XVIII.

Paralelamente, o racionalismo imperava na Europa, transmitindo a confiança de que a razão era o principal instrumento do homem para enfrentar os desafios da vida e equacionar os problemas que os rodeavam. (COTRIM2, 2006).

Os avanços tecnológicos do século XVIII fizeram surgir um novo mito, a ideia de progresso. Disseminou-se, desse modo, a crença de que a razão, a ciência e a tecnologia tinham condição de impulsionar o desenvolvimento numa marcha contínua em direção verdade e ao progresso humano.

Nesse sentido, o escritor Jostim Garder apresenta a justificativa para o nome do movimento "iluminista".

“[...] A maioria dos filósofos do iluminismo tinha uma crença inabalável na razão humana [...] Assim, os filósofos iluministas consideravam sua tarefa criar um alicerce para a moral, a ética e a religião que estivesse em sintonia com a razão imutável do homem. [...] Dizia-se, então, que era chegado o momento de 'iluminar' as amplas camadas da população. [...] Os filósofos iluministas diziam que somente quando a razão e o conhecimento se tivessem difundido entre todos é que a humanidade faria grandes progressos. Era apenas uma questão de tempo para que desaparecessem a irracionalidade e a ignorância e surgisse uma humanidade iluminada, esclarecida. [...] Os filósofos iluministas franceses não se contentaram apenas com as concepções teóricas sobre o lugar do homem na sociedade. Eles lutaram ativamente por aquilo que chamaram de 'direitos naturais' dos cidadãos [...] No que diz respeito à religião, a moral, e à política, o indivíduo precisava ter assegurado o seu direito à liberdade de pensamento e de expressão de seus pontos de vista. Além disso, lutou-se contra a escravidão e por um tratamento mais humano dos infratores das leis". (GARDER, Jostein 1998: 338-340 apud BRAICK e MOTA3, 2006)

Todas essas ideías se originam em um período denominado moderno, o qual tem como início uma série de transformações nas

${ }^{1}$ Período histórico que teve como característica o Absolutismo Monárquico, a força da Igreja Católica que legitimava o poder político do Rei como sendo um poder divino. 
sociedades européias que se relacionaram com a conclusão de uma nova mentalidade. Tal projeto se vincula com vários fatos como: a passagem do feudalismo para o capitalismo; formação do Estado-nação; emergência da burguesia e o movimento da reforma.

O movimento da reforma provocou a quebra da unidade religiosa européia e rompeu com a concepção passiva do homem, entregue unicamente aos desígnios divinos, reconhecendo o trabalho humano como fonte de graça divina e origem legítima da riqueza e da felicidade. A reforma também concebeu a razão humana como extensão do poder divino, o que colocava o homem em condição de pensar livremente e responsabilizar-se por seus atos de forma autônoma. Isso levou ao desenvolvimento do racionalismo acreditando na capacidade da razão intervir no mundo, organizar a sociedade e aperfeiçoar a vida humana. (COTRIM2, 2006).

$\mathrm{O}$ movimento cultural que marcou essas transformações sócio-culturais europeias é reconhecido como Renascimento, que propiciou o desenvolvimento de uma mentalidade racionalista, revelando maior disposição para investigar os problemas do mundo. O homem moderno aguçou seu espírito de observação sobre a natureza, dedicou mais tempo à pesquisa, e as experimentações tornaram a mente aberta ao livre exame do mundo. (COTRIM2, 2006).

A partir de meados do século XVIII, o capitalismo foi se consolidando em diversos países. Esse processo de transformação, do qual está vinculado a Revolução industrial, atinge amplos setores da economia.

Paralelamente, aexpansãoeaconsolidação do capitalismo trouxeram, também, novas formas de exploração do trabalho humano. Isso gerou uma série de conflitos entre dois grandes grupos sociais e seus diversos segmentos, de um lado a burguesia e de outro os trabalhadores.

Conforme bem aborda Cotrim2 (2006), a Revolução Francesa, além dos anseios próprios da burguesia, trouxe as aspirações dos trabalhadores urbanos e do campesinato. Essas aspirações iriam gerar, em seus desdobramentos, as lutas e correntes socialistas do século XIX que denunciaram a exploração do trabalho no contexto do capitalismo industrial. Ao mesmo tempo, o notório otimismo em relação aos poderes da razão que dominaram a idade moderna e parte do século XIX foi, em muitos sentidos, minguando ao longo do período contemporâneo. Novas reflexões lançaram desconfiança em relação aos diversos frutos, tantas vezes inesperados da ciência e da tecnologia.

Os complexos caminhos da sociedade contemporânea nos colocaram diante de grandes questões como as desigualdades sociais e os rumos do desenvolvimento tecnológico-científico, entre outros. Todo esse progresso garantiu bem estar à população? Quais as relações do processo civilizatório e a felicidade humana?

O desenvolvimento tecnológico trouxe expressivos indicadores de ganhos para a qualidade da vida do homem, derivados do progresso científico e do aumento da produtividade. Mas, quais os efeitos de todos esses avanços e conquistas no tocante à felicidade? Ou seja, da nossa satisfação em viver um grau de realização que esperamos e tentamos alcançar? Até que ponto a civilização moderna "alcança" a todas as camadas da sociedade com seus avanços tecnológicos? Até que ponto a civilização moderna tem facilitado ou dificultado a busca da felicidade?

A promessa de felicidade dizia respeito à expansão das oportunidades e principalmente da capacidade das pessoas em geral de viverem a altura do seu melhor potencial, escolhendo seu próprio destino. O que deu errado no projeto iluminista foi dar ênfase desmesurada à transformação e a conquista do mundo objetivo em detrimento de uma atenção maior à questão dos desejos e ao lado contemplativo da realização humana. (GIANNETTI4 , 2002).

O domínio da natureza pelo homem era uma peça fundamental no projeto iluminista, mas ele viria acompanhado de duas outras conquistas paralelas. A primeira se refere a crescente capacidade de aperfeiçoar a natureza humana por meio da educação e de um ambiente próprio para o seu pleno desenvolvimento. Em segundo lugar, seria a crescente capacidade dos governos em fomentar o bem estar da maioria por meio de políticas e de uma legislação racional. (GIANNETTI4, 2002).

Entretanto, fazendo uma análise crítica às abordagens trabalhadas pelo autor, podemos afirmar que ocorreu expansão das oportunidades, mas se questiona para quem 
estavam dirigidas. Quem seria alvo desses avanços? O projeto iluminista, conforme já discutido anteriormente, não era um projeto popular, era um projeto burguês. E pensando sobre essa premissa fica claro que a felicidade para todos seria uma utopia ou um alcance subjetivo.

$\mathrm{O}$ projeto educacional da sociedade capitalista tem sido voltado para a burguesia, objetivando a manutenção do estado burguês. Não se configura uma educação libertadora que promova uma transformação social.

Cotrim2 (2006) utiliza o pensamento de Marx para conceituar o papel do Estado e afirma que ele não é um simples mediador de grupos rivais, isto é, entre aqueles que protagonizam a luta de classes. O Estado é uma instituição que interfere nessa luta de forma parcial, quase sempre tomando partido das classes sociais dominantes. Assim, a função do Estado é garantir o domínio de classe. Nascido dos conflitos de classe, o Estado tornou-se a instituição controlada pela classe mais poderosa, a classe dominante. Assim, na maior parte dos Estados históricos, os direitos concedidos aos cidadãos são regulados de acordo com as posses dos referidos cidadãos, pelo que se evidencia ser o Estado um organismo para a proteção dos que possuem contra os que não possuem.

\section{Discutindo o conceito de pós- modernidade}

Para alguns autores, não existe necessariamente uma condição pós-moderna, mas a transformação radical das bases da modernidade, como o fim da ideia do iluminismo e descrença na racionalidade.

A pós-modernidade é fruto dos avanços políticos e culturais da modernidade. A pósmodernidade nasce da modernidade, na verdade, a modernidade era o período de "gestação da pós-modernidade", colocando que os avanços tecnológicos, como a microeletrônica, a internet, a robótica, que hoje permitem uma nova forma de vivenciar o contemporâneo, são, na realidade, frutos da própria modernidade. Para Harvey, a modernidade é condição para pós-modernidade. É a emergência de novas maneiras dominantes de experimentarmos o tempo e o espaço na sociedade contemporânea". (HARVEY5, 1998).

A pós-modernidade teve início a partir dos anos de 1960. As raízes da discussão encontram-se na crise cultural que se faz sentir principalmente a partir do pós-guerra.

O desencanto que se instala na cultura é acompanhado da crise de conceitos fundamentais ao pensamento moderno, tais como verdade, razão e progresso. O projeto de modernidade parece constituir um grande sonho que a humanidade elaborou para si mesma, ou ainda um projeto de razão como libertadora. O discurso iluminista de emancipação pela revolução, ou pelo saber, sustenta essa confiança na capacidade da razão. (CHEVITARESE6, 2001).

A pós-modernidade não seria o fim da modernidade, mas o desencanto da modernidade com o que não deu certo. $\mathrm{O}$ autor recorre às ideias de Harvey dizendo que o projeto de modernidade entrou em foco no século XVIII. Esse projeto equivalia a um extraordinário esforço intelectual dos pensadores iluministas para desenvolver a ciência, a razão e as leis universais. A ideia era usar o acúmulo de conhecimento gerado por muitas pessoas, trabalhando livre e criativamente em busca da emancipação humana e do enriquecimento da vida diária.

Entretanto, o que se observou foi que a expectativa, quanto aos frutos da ciência, foi dolorosamente interrompida por eventos que marcaram a sociedade atual. O principal deles foi sem dúvida à catástrofe da II Guerra Mundial. A ciência perdeu o seu valor, resultado da desilusão com os benefícios que associados à tecnologia trouxe à humanidade. $\mathrm{Na}$ verdade, a ciência acabou gerando duas guerras mundiais resultante da invenção de um armamento bélico poderoso e destrutivo. Todo esse desenvolvimento científico culminou numa crise ecológica mundial. Nesse sentido, podemos duvidar dos reais benefícios trazidos pelo progresso, apontando ainda para uma dependência tecnológica. A pós-modernidade configura-se como uma reação cultural, ou seja, uma perda de confiança no potencial universal do projeto iluminista.

Partindo da concepção de Yudicel (1990) podemos afirmar que a pós-modernidade não deve ser entendida como outro estágio 
que se atinge depois de se ter passado pela modernidade. $\mathrm{O}$ autor entende que a pósmodernidade deve ser a insistência num questionamento crítico da sociedade moderna das suas desigualdades sociais e das formas de participação no debate político.

\section{As consequências da modernidade à condição humana}

O século XVIII, marcado pelo advento da Revolução Francesa, vem trazer profundas transformações a existência humana.

Esse período conclamou o homem a que selibertassede todas as dependênciashistóricas no que se refere ao Estado, a religião, à moral e à economia, deixando de ser, assim, um indivíduo preso a vínculos de caráter político, agrário, corporativo e religioso; erguia-se assim, o grito por liberdade e igualdade, a crença na plena liberdade de movimento do indivíduo em todos os relacionamentos sociais e intelectuais. A liberdade permitiria que a substância nobre comum a todos viesse à tona, que a natureza depositara em todo o homem e que a sociedade e a história não haviam feito mais do que deformar. (SIMEL7 apud VELHO, 1967)

Entretanto, com essa maior liberdade adquirida pelo homem, o século XVIII exigiu do mesmo a sua especialização e também do seu trabalho, tornando-o mais dependente das atividades suplementares de todos os outros homens.

Através da divisão econômica do trabalho, por outro ideal se levantou os indivíduos liberados dos vínculos históricos e que agora desejavam distinguir-se um do outro. A escala dos valores já não é constituída pelo ser humano geral, mas pela unicidade e insubstitubilidade, mas ao mesmo tempo dependente do trabalho dos outros homens. Exigindo que o indivíduo apele para o extremo no que se refere à "exclusividade" e particularização para preservar sua existência, o que acaba incentivando a competitividade.

Simmel7, ao abordar as características da modernidade, trabalha com a noção de metrópole que se constitui o lócus privilegiado para expressar o modo de vida moderno pautado na racionalidade do homem conforme as ideias iluministas.

Ao trabalhar com a concepção de metrópole o autor irá refletir sobre os impactos da vida moderna na subjetividade humana, de como essa vivência irá interferir no conteúdo individual do homem. A vida metropolitana requer um nível elevado de consciência e inteligência do homem, pois a intelectualidade se destina a preservar a subjetividade contra o poder avançado da vida na metrópole; sendo assim o ser humano resiste a uniformização do indivíduo.

Nesse sentido, a metrópole, enquanto sede mais alta da economia do trabalho, requer que o homem se especialize o tempo todo para preservar seu lugar, seu espaço e não ser substituído pelo outro. O indivíduo procura ao extremo, exclusividade para preservar sua essência mais pessoal a fim de manter-se perceptível até para si próprio.

A racionalidade imposta ao homem faz com que as relações racionais entre os homens sejam sempre comparadas, como se o ser humano fosse redutível a um número e a intelectualidade pudesse distanciar o homem do sentimento.

$\mathrm{O}$ homem metropolitano reage com a cabeça e não com o coração. A metrópole se caracteriza pela grande quantidade e diversidade de estímulos gerando um "excesso", provocando uma adaptação do nível individual, o que Simmel denominou de atitude blasé que seria a intensificação da intelectualidade metropolitana. Uma vida desregrada de prazer torna uma pessoa blasé porque agita os nervos até seu ponto de mais forte reatividade por um tempo tão longo que eles param de reagir. Essa atitide seria então a dificuldade de discriminar, os objetos são percebidos, mais antes que o significado e valores sejam atributos denominador, aparecem num plano fosco e uniforme.

A atitude blasé seria um comportamento de adaptação, recusa de reagir, autopreservação do indivíduo na cidade grande, um tipo de reserva fazendo os indivíduos parecerem frios e desalmados. Essa reserva confere ao indivíduo uma quantidade de liberdade individual, a reserva e a indiferença recíprocas e as condições de vida intelectual nunca são 
sentidas fortemente pelo indivíduo no que se refere a sua independência.

Essa antipatia protegeria os indivíduos do perigo da metrópole, contribuindo para a manutenção desse estilo de vida. O que aparece no estilo de vida, como dissociação da realidade, é apenas uma de suas formas elementares de socialização. A metrópole seria o local da liberdade e também da solidão.

Velho8 (1994), ao refletir sobre os escritos de Simmel, aponta que o mesmo via na multiplicidade e diferenciação de domínios e níveis de realidade da sociedade moderna um desafio à integridade do indivíduo pscicológico. A modernidade da metrópole significaria um impedimento ao desenvolvimento integrado do indivíduo.

O autor tenta relativizar essa concepção de que a vida na metrópole ameaça o desenvolvimento integrado do indivíduo, ao afirmar que é próprio da metrópole e das sociedades complexas um campo de possibilidades em que é possível uma interação entre indivíduos em meio a tanta diversidade, onde se cruzam trajetórias e trilhas sociológicas e culturais. Apesar dos mundos estarem demarcados por fronteiras étnicas, sociológicas e culturais, a experiência dos grandes centros urbanos tenderam a relativizar essas fronteiras apontando a existência de uma rede de relações nas sociedades complexas.

Por mais significativa e inclusivas que podem ser categorias como família e parentesco, bairro e vizinhança, origem étnica, grupos de status, estratos e classes sociais registravam-se circulação, interações sociais associadas a experiências, combinações e identidades particulares, individualizadas. O mercado de trabalho e o trabalho, a vida política com suas transformações são, sem dúvida, fatores estimuladores dessas "travessias sociológicas" com maiores ou menores custos individuais (VELHO8,1994).

O processo de urbanização é um exemplo paradigmático desse fenômeno, mais recentemente, as cidades do terceiro mundo com êxodo rural, migrações, explosões demográficas e marginalidade apresentam um quadro flagrante da fragilidade e impotência da esmagadora maioria dos indivíduos e das categorias sociais.
$\mathrm{O}$ indivíduo, na sociedade moderna, se constitui ponto de interseção de vários mundos; através da organização social, da interação entre indivíduos e suas redes de relações, e ainda, através da negociação da realidade, sendo que essa idéia onde a ideia de negociação seria a ideia de reconhecimento da diferença como elemento constitutivo da sociedade.

O conflito, a troca, a aliança e a interação são elementos constitutivos da vida social. A negociação da realidade é viabilizada através da linguagem, que é produtora de significados, possibilitando assim, a coexistência de discursos e visões de mundo. A cultura, enquanto comunicação, não exclui as diferenças; ao contrário, vive delas. A diferença no nível dos discursos e das representações não estão limitadas às fronteiras sócio-econômicas, estão associadas ao mundo simbólico, manifestado através da linguagem e de códigos que exercem um papel socializador.

A fragmentação das relações e papéis sociais na sociedade moderna demarca domínios distintos. O jogo de papéis e identidades nas grandes metrópoles caracteriza esse estilo de vida moderno. Os indivíduos vivem múltiplos papéis em função dos diferentes planos em que se movem vivendo essas pessoas em diferentes planos simultaneamente. $\mathrm{Na}$ sociedade complexa, a coexistência de diferentes mundos constitui a sua própria dinâmica. $\mathrm{O}$ individualismo moderno, metropolitano, não exclui a vivência e o englobamento por unidades abrangentes e experiências comunitárias, não elimina o nível de escolha e opção do indivíduo.

Velho8 (1994) chama a atenção para o fato de que os indivíduos, mesmo nas passagens e trânsitos entre os domínios e experiências mais diferenciadas, mantêm uma identidade vinculada a grupos de referências como família, etnia, região, vizinhança, religião, etc. A tendência à fragmentação não anula as referências do indivíduo que podem ser acionadas em momentos estratégicos. Discorda de Simmel no que se refere à fragmentação ao dizer que ela não deve ser entendida como estraçalhamento do indivíduo psicológico. $\mathrm{O}$ trânsito entre os diferentes mundos é possível, 
graças à natureza simbólica da construção social da realidade.

Ainda se reportando a Simmel, Velho8 (1994) afirma que a utilização de diferentes códigos e discursos relativiza a atitude blasé, pois não é o mesmo indivíduo, único que recebe passivamente estímulos múltiplos e diferenciados. A noção de cultura subjetiva do próprio Simmel nos permite pensar que esta pode ser construída em múltiplos planos, dependendo de cada indivíduo, permitindo que os indivíduos estejam permanentemente sendo reconstruídos no processo de construção social da realidade.

Um outro elemento importante que traz profundas transformações culturais nas sociedade modernas se refere ao processo de globalização. A globalização refere-se àqueles processos, atuantes numa escala global, que atravessam fronteiras nacionais, integrando e conectando comunidades e organizações em novas combinações de espaço e tempo. A globalização implica um movimento de distanciamento da idéia sociológica clássica da sociedade como um sistema bem delimitado e sua substituição por uma perspectiva que se concentra na forma como a vida social está ordenada ao longo do tempo e do espaço.

Entretanto, o crescente avanço tecnológico não deve significar a eliminação de modos de vida tradicionais. No mundo globalizado, as novas tecnologias e comportamentos devem conviver com hábitos e costumes das antigas gerações.

Independentemente de qual seja a ordem política, econômica e mundial, um aspecto da era da globalização mantém-se cada vez mais poderoso e mundializado: o sistema de produção e consumo, objetivando arregimentar todos os tipos de consumidores e, independentemente das diferenças culturais, incentivando o consumo de massa. A necessidade do consumo passa por cima de qualquer diferença cultural.

Para Castells9 (1999), o processo de globalização se constitui uma ameaça detectada em todas as sociedades pela maior parte da humanidade neste fim de milênio, pois, dissolve a autonomia das instituições, organizações e sistemas de comunicação local onde vivem as pessoas. Aponta que uma outra ameaça se refere à formação de redes e à flexibilidade que tornam praticamente indistintas as fronteiras de participação e envolvimento, individualizam as relações sociais de produção e provocam a instabilidade estrutural do trabalho, do tempo e do espaço.

Para Bauman10 (1998) a distinção contemporânea sobre o contínuo do tempo é o aspecto mais profundo da mentalidade moderna. Os homens modernos viveram num tempo-espaço sólido, durável, duro recipiente em que os atos humanos podiam cunharse seguros. Liberdade era a necessidade conhecida, mas também, a decisão de agir com esse conhecimento.

Entretanto, para os homens e as mulheres da pós-modernidade, esse mundo sólido, estruturado, desapareceu. Conforme aponta Bauman10 (1998) o mundo em que o homem tem vivido é formado de regras que são feitas e refeitas no curso da disputa. Viver nesse mundo é jogar bem e usar ao máximo suas habilidades, pois mundo tem se tornado mais frágil em todas as relações. Enfim, as relações que perpassam o mundo contemporâneo são simples, sem compromisso para durar não mais do que a satisfação derivada. $\mathrm{O}$ mundo construído de objetos duráveis foi substituído pelo de produtos disponíveis e projetados para imediata obsolescência.

Para o autor acima citado, no jogo da vida dos homens e mulheres pós-modernos, as regras não param de mudar no curso da disputa. A estratégia é manter curto cada jogo, tomar cuidado com compromissos em longo prazo, recusar-se a fixar e não se prender a lugar nenhum. O tempo já não estrutura mais o espaço, o que conta é a habilidade de se mover e não ficar parado. Viver só o presente, um dia de cada vez e não pensar no passado e nem no futuro. Na sociedade pós-moderna estamos de uma forma ou de outra, no corpo ou no espírito, aqui e agora ou no futuro antecipado, em movimento.

Bauman10 (1998) utiliza duas categorias para caracterizar a divisão da sociedade pós-moderna; a posição entre os turistas e os vagabundos. Para o autor, estamos todos traçados num contínuo estendido entre os polos do "turista perfeito" e o "vagabundo incurável". Os nossos lugares estão traçados segundo o grau de liberdade que possuímos para escolher nossos itinerários de vida. 
Nesse sentido, a liberdade de escolha na sociedade pós-moderna é o maior fator de estratificação, quanto mais liberdade de escolha se tem, mais alta é a posição alcançada na hierarquia social pós-moderna. Quanto mais repulsiva e detestável a sorte do vagabundo, mais toleráveis são os pequenos incômodos e os grandes riscos da vida do turista.

O turista significa o evitar de uma identidade que se fixa, a arte de misturar os sólidos e desprender o fixo. É dos turistas a façanha de não pertencer a lugar nenhum, estar dentro e ao mesmo tempo fora. É deles o acesso aos dois mundos, A pessoa deve poder mudar quando as necessidades impelem ou os sonhos solicitam. A essa aptidão, os turistas dão o nome de liberdade, autonomia ou independência. $\mathrm{O}$ mesmo não acontece com o vagabundo pelas razões da lógica da hierarquia social.

Os turistas possuem o controle situacional, escolher com que parte do mundo se quer interfacear e quando desligar a conexão. Os prazeres da vida colocam o sonho da nostalgia acima das realidades da casa. A peculiaridade da vida turística é não chegar.

Já os vagabundos se movem porque foram impelidos por trás, veem sua situação como qualquer coisa que não a manifestação da liberdade. Para eles, estar livre significa não ter que viajar de um lado para o outro e sim ter um lar e ser permitido estar dentro dele. São considerados os mutantes da evolução pós-moderna, os restos do mundo que se dedicaram a serviço dos turistas. Os vagabundos se movem porque acham o mundo insuportavelmente inóspito, não têm outra escolha. Pode-se viver com as ambiguidades da incerteza que saturam a vida do turista, só porque as certezas da vagabundagem são tão inequivocadamente asquerosas e repugnantes.

Os vagabundos são as vítimas do mundo que transformou os turistas em seus heróis são "funcionais a essa sociedade"

\section{Desafios à condição humana nas sociedades pós-modernas}

Tomando como referência às ideias de Manzini-Covre11 (1995), como pensar em novas formas de vida mais gratificante no mundo contemporâneo?

A pós-modernidade acabou por instituir uma crise cultural em função da necessidade de revisão de conceitos fundamentais ao processo moderno.

Nessa perspectiva, Manzini-Covre11 (1995) aponta que essas mudanças culturais e também estruturais podem ser materializadas no que a autora denomina de formas sociais fragmentárias.

Estas, por sua vez, podem ser entendidas como organizações e grupos sociais ordenados por uma razão ou um aspecto da cultura que se opõe a razão técnica. Essas formas fragmentárias seriam orientadas por valores não de fins imediatos, mas também como mediatizadores como a solidariedade, a amizade, a afetividade, a nobreza. Orientadas não por valores e práticas pretensamente neutros, mas com a capacidade e vontade políticas voltadas para o interesses de grupos específicos da sociedade mais ampla.

Destacam-se como instituições que trabalham nessa perspectiva; as Organizações não governamentais, os movimentos sociais, que dizem respeito a organizações e grupos sociais ordenados por uma razão ou um aspecto da cultura que tende a se opor à razão técnica.

Concordamos com Yudicel (1990) que afirma que a sociedade pós-moderna é exatamente aquela em que os grupos sociais menos favorecidos se organizam para defender os seus direitos e para exigir a transformação de uma realidade que exclui.

Manzini-Covre11 (1995) aponta a ideia de construção de uma cidadania que expressaria a cidadania das formas fragmentárias. Destaca que a família- por entender se constituir o lócus privilegiado de concretização da afetividade, amizade e solidariedade- seria a organização por excelência para o alcance do que denomina de cidadania nova.

A autora citado, para trabalhar com a concepção de uma "cidadania nova", apresenta outros dois tipos de cidadania. Primeiramente, discute a noção de cidadania do status quo que objetiva a manutenção do poder exercido pelo Estado, onde os sujeitos não existem e sim se deixam usar pelo Estado, se constituindo o tipo dominante de cidadania, 
passiva e consumista que se centra no ter; objetiva um comportamento de massa do homem, adequado aos grupos poderosos que podem gerir a sociedade autoritariamente com um "consentimento "da população.

Um segundo tipo de cidadania seria a contrapartida da cidadania do status quo, porque se refere à apropriação do espaço da contradição entre grupos dominados e a população a ser cidadã. São os demandatários fazendo valer suas propostas de políticas sociais de atendimento dos direitos sociais, se caracterizaria por uma cidadania centrada no agir.

Finalmente, a autora traz a concepção do que seria uma cidadania nova, que fugiria do âmbito de construir melhores possibilidades de vida para a humanidade por via revolucionária, entendida como uma cidadania centrada no sentir e na importância da interação do sujeito com seus diferentes "eus", na construção de identidades nas quais o sujeito não existe em si é um sujeito em constituição. A cidadania nova depende de que o novo emerja de "dentro" desta pessoa e assim seja reconhecido, incorporado, podendo vir a ser instituinte de novas formas inovadoras de alteridade para o avanço social seria a revolução da subjetividade.

A cidadania nova depende de que o novo emerge de "dentro" nesta pessoa seja reconhecido, incorporado, podendo vir a ser instituinte de novas formas inovadoras de alteridade para o avanço social seria a revolução da subjetividade. Seria, então, pensar que o processo de estar vivo implica reconhecer que a felicidade é alegria e sofrimento, de que não se é tão impotente assim diante de nossa existência.

\section{Concluindo}

A mundialização do capital e as novas tecnologias interferem em aspectos importantes da sociedade como a subjetividade, a identidade e a cultura.

A pós-modernidade pode ser caracterizada como uma reação à cultura e ao modo como se desenvolveram historicamente os ideais da modernidade, associada à perda de otimismo e confiança no potencial universal do projeto moderno. Configura-se como uma rejeição à tentativa de colonização pela ciência das demais esferas da vida do homem. A pósmodernidade não abandona os imperativos da racionalidade crítica, ao contrário, leva a crítica às mais profundas consequências, questionando os conceitos pressupostos pela modernidade. (CHEVITARESE6 ,2000)

De acordo com as reflexões de Bauman10 (1998), o homem pós-moderno é aquele facilmente adaptável o qual convive, a todo momento, com as realidades distintas e consegue sobreviver a todas elas. Entretanto, questionase se é possível que esse homem busque um posicionamento mais autônomo diante da vida?

(...) “O homem sempre quererá ser mais do que é, sempre se revoltará contra as limitações de sua natureza (...) Se alguma vez se desvanecesse o anseio de tudo conhecer e tudo poder, o homem já não seria mais homem. Assim, ele sempre necessitará da ciência, para desvendar todos os possíveis segredos da natureza e dominá-la. E sempre necessitará da arte para se familiarizar com a sua própria vida e com aquela parte do real que a imaginação lhe diz ainda não ter sido devassada (...)"(ERNST FISCHER 1977, apud COTRIM 2,2006).

Nessa perspectiva, o homem, enquanto sujeito imperfeito dada a sua natureza, sempre buscará superar as suas limitações, sempre se verá como parte de uma realidade infinita. Essa característica é que mantém viva a possibilidade de o homem reivindicar direitos e exigir a transformação de uma realidade que os reprimi, sufoca e exclui.

\section{Referências}

YUDICE, G. "Entrevista: O pós-moderno em debate". in Revista Ciência Hoje, março de 1999.

COTRIM, G. Fundamentos da Filosofia: história e grandes temas, 16 ed, São Paulo: Saraiva, 2006. 
BRAICK, P.R e MOTA, M.B. História: das cavernas ao terceiro milênio. $2^{\mathrm{a}}$ edição. São Paulo: Moderna, 2006.

GIANNETTI, E. Felicidade, São Paulo: Cia das Letras, 2002. p 09-55.

HARVEY, D. Condição Pós-Moderna, São Paulo: Edições Loyola, 1993. (pág 13-114)

CHEVITARESE, L. "As razões da pósmodernidade". in Análogos. Anais da I SAFPUC, Rio de janeiro: Boolink. (ISB 85-8831907-1).

SIMMEL, G. "A metrópole e a vida mental". in VELHO, O. (org). O Fenômeno Urbano. Rio de Janeiro : Zahar. 1967.

VELHO, G. Projeto e Metamorfose: antropologia das sociedades complexas. Rio de Janeiro: Zahar. 1994. p 11-48.

CASTELLS, M. O Poder da Identidade, São Paulo: Paz e Terra, 1999. p 21-92.

BAUMAN,Z. O mal estar da pós-modernidade. Rio de Janeiro: Jorge Zahar. 1998 (pág 106120).

Endereço para Correspondência:

Karin Alves do Amaral Escobar karinalvesamaral@ig.com.br Rua Miguel Cervantes, 107 apt 102 São João Batista - Volta Redonda CEP: 27285-175

Informações bibliográficas:

Conforme a NBR 6023.2002 da Associacão Brasileira de Normas Técnicas (ABNT), este texto científico publicado em periódico eletrônico deve ser citado da seguinte forma: ESCOBAR, Karin Alves do Amaral. Modernidade e pós-modernidade: promessas, dilemas e desafios à condição humana. Cadernos UniFOA. Volta Redonda, ano V, n. 12, abril ESCOBAR, Kas 2010. Disponível em: $<$ http://www.unifoa.edu.br/cadernos/edicao/12/71.pdf $>$ 